\title{
Factors Related to Employment Situation among Korean Cancer Survivors: Results from a Population-Based Study
}

\author{
Ari Lee, Jong-Eun Lee*
}

\begin{abstract}
Background: Due to the increased incidence and survival rate of cancer, the number of cancer survivors has been increasing. In addition, many problems have been reported regarding the employment of these survivors. Therefore, this study aims to investigate the employment situation of cancer survivors and associated factors. Methods: We analyzed data from the Korean National Health and Nutrition Examination Survey (2010-2014), which is a nationwide cross-sectional health survey, and included a total of 1,060 participants who were diagnosed with cancer. Multivariate logistic regression analysis was conducted to investigate the factors associated with the participants' employment situation. Results: The employment rate among cancer survivors was $42.0 \%$. The variables found to be associated with being employed were male gender, younger age, higher household income level, educational level at middle school level or under, and not having activity limitations. Conclusion: These findings suggest that, in addition to cancerrelated factors, general characteristics such as gender, age, household income, and education level are important factors associated with the employment status of Korean cancer survivors.
\end{abstract}

Keywords: Employment- work- cancer- survivor

Asian Pac J Cancer Prev, 20 (1), 33-40

\section{Introduction}

According to the World Health Organization (WHO)'s World Cancer Report in 2014, there were approximately 14 million cancer patients in 2012 alone. Furthermore, the incidence of cancer is expected to increase by $70 \%$ in the following two decades (Stewart and Wild, 2014). In South Korea, the incidence of cancer was 445.7 patients per 100,000 population in 2013 (male 449.9, female 441.5), and this rate shows a tendency to increase annually (Statistics Korea, 2016a). Despite the increase in the incidence of cancer, due to e.g., earlier diagnoses, progress in treatment modalities have helped to improve the survival rate of cancer patients each year. The five-year survival rate has improved from 41.2\% in 1995 up to $69.4 \%$ in 2013. Moreover, the 10 -year survival rate has also increased from $38.2 \%$ (1993-1995) to $56.9 \%$ (2004-2008) (National Cancer Information Center, 2016).

Cancer survivors typically progress through a process that begins with a cancer diagnosis followed by surgical procedures, chemotherapy and/or radiation therapy, which may cause various physical, mental, and social side effects (Teo et al., 2015). So far, previous studies have predominantly focused on the physical and mental aspects of treatment. However, with the recent increase in survival rates, more attention is being devoted to recognizing cancer survivors as members of the community and to facilitate cancer survivors to adapt their social life (Clarke et al., 2015; Nekhlyudov et al., 2016; Tevaarwerk et al., 2016). Based on previous reports, employment positively affects the individual in terms of physical and mental well-being, with significant implications for economic stabilization and recovery of self-esteem (Amir et al., 2008; Cooper et al., 2013). For this reason, developed countries including the United States, have implemented laws that prohibit discrimination against cancer survivors (Gibson, 1998). According to previous studies the probability that cancer survivors will return to their job shows a range from 23-84\% (Taskila and Lindbohm, 2007; Amir and Brocky, 2009; Mehnert, 2011). In addition, the factors associated with being employed included men, younger age, higher level of education, higher level of income, type of cancer, fatigue, activity limitation, relationship with employer, and uncertainty of the disease (Schultz et al., 2002; Taskila and Lindbohm, 2007; Amir et al., 2008; Short et al., 2008; Amir and Brocky, 2009; Grunfeld et al., 2010; Mehnert 2011; van Muijen et al., 2013; Lindbohm et al., 2014).

In South Korea, a previous longitudinal study on the influence of cancer on the employment of status of cancer survivors aged between 25 and 55 years old based on national health insurance data from 2001 to 2006 revealed that cancer survivors, after being diagnosed with cancer, were more likely to lose their job and that chance of returning to the original work place was low (Park et al., 2009). According to a National Cancer Center study that 
was conducted with 305 male cancer patients, $53 \%$ of the study participants lost their job, and only $23 \%$ succeeded in finding a new one.

In this study, the researchers utilized source data from the Korean National Health and Nutrition Survey (KNHANES), which is conducted annually, to identify the employment situation of cancer survivors and the factors that affect these results according to two categories, i.e., general characteristics and cancer-related factors.

\section{Materials and Methods}

\section{Data and study population}

For this study, data from 5 years (2010-2014) of the KNHANES were gathered and used for the analysis. The KNHANES is conducted annually, with the aim of examining the health situation of the Korean population, as well as their health behavior, food, and nutrition situation, and to calculate representative and national statistics.

The inclusion criteria were that participants 1) were aged 19 and over, and 2) reported being diagnosed with cancer by a doctor. According to the definition of the American Cancer Society (ACS), cancer survivors include not only patients who completely recover from cancer but also patients who are being treated for cancer while living their normal lives (ACS, 2016). For the five-year period (2010-2014) of interest, the total number of participants who participated in the survey was 41,102 . Of these, the number of cancer survivors, i.e., those who answered that they had been diagnosed with cancer by a doctor, was 1,092. In this study, 32 cases with missing values were excluded, and a total of 1,060 participants (male 390, female 670) were finally included in the analysis.

Source data were downloaded from the webpage of the KNHANES located within the Korea Centers for Disease Control and Prevention (KCDC) (http://knhanes. cdc.go.kr/) as an open raw data file. The KNHANES was conducted after Institutional Review Board (IRB) approval from the KCDC and all participants signed an informed consent form. In addition, this study was conducted after being reviewed by the IRB of Catholic University of Korea, which issued approval.

\section{Measures \\ General characteristics}

Gender, age, marital status, place of residence, income, and educational level were included. The age groups were divided into those in their 20/30s, 40/50s, and 60s and above. Marital status was divided into 'yes' (the respondent was married and living with a current spouse) or 'no' (the respondent was not living with a current spouse because the respondent was single, separated, widowed, or divorced). The places of residence were divided into urban and rural areas. Income levels were divided into quartiles based on the average monthly equalized household income (=average monthly household income/ $\checkmark$ number of household members), which corrects the total household income for the number of household members. Educational level was divided into middle school graduates or lower and high school graduates or higher.

\section{Cancer-related factors}

The cancer-related factors included the type of cancer, time since the diagnosis, full recovery, ongoing treatment, perceived health, and activity limitation. Type of cancer was divided into eight categories (i.e., stomach cancer, liver cancer, colon cancer, lung cancer, breast cancer, uterine cancer, thyroid cancer, and other types of cancer). The time since the diagnosis of cancer was sub-divided into less than 5 years, 5-10 years, and 10 years or more. For full recovery, this variable was defined as whether the patient was still suffering from the disease since the initial diagnosis (yes; no). Additionally, ongoing treatment status was defined as whether the participant was still receiving cancer treatment. Perceived health was divided into three levels: good, moderate and bad. The activity limitation variable was grouped to indicate whether the patient experienced limitations in his or her daily or social life activities due to health issues.

\section{Employment situation of the cancer survivors}

To understand the employment situation of cancer survivors, employment status, occupational classification, status of workers, employment type, type of working time, and working hours per week were used as the variables for employed participants, while the cause of unemployment was included for the unemployed participants.

\section{Employment status}

The subjects were divided into employed (persons who during the reference week were working for a paid job for at least one hour, without pay in a family business for 18 hours or more) (OECD, 2017; Statistics Korea, 2016b) and unemployed (persons who did not work at all for an income during the survey period).

\section{Occupational classification}

The 6th version of the Korean standard classification of occupations was used to classify the occupations into administration/office jobs (managers, experts, office clerks, and other related occupations), services/sales (service providers and sales clerks), and laborers (skilled agricultural or fishery workers, technicians, equipment or machine operators, equipment assembly workers, unskilled laborers, and other occupations for the related functions).

\section{Status of workers}

This variable was divided into wage/salary workers (persons who were hired by other persons or companies and worked for them in return for a wage), self-employed persons and employers (business owners), and unpaid family workers (persons who worked for a business operated by a member of their family without a wage for at least 18 hours per week).

\section{Employment type of wage/Salary workers}

Participants were grouped into regular workers and non-regular workers. The definition of regular workers was permanent workers including those who were recruited in accordance with a certain employment process and complied with the human resource rules of the 
company or those who could receive bonuses, severance allowances, or other benefits, with the term of employment contract being at least one year or longer. The definition of non-regular workers was temporary workers included those with employment contract terms more than onemonth but less than a full year, those with an employment contract period less than a month, and day-job workers (Lee et al., 2010).

Type of contract of wage/Salary workers

The participants were defined as either full-time (persons with a contract requiring at least 36 hours of work per week) or part-time workers (persons working less than 36 hours per week).

\section{Average working hours per week}

The participants' total working hours per week, including overtime and night shifts, were classified into 'less than 40 hours', '40-52 hours', and 'more than 52 hours'.

\section{Reasons for unemployment}

The most substantive reasons that people were not working were classified into seven categories (not seeing the necessity of working, attending school or a training course, retiring due to age or other reasons, having health concerns, providing childcare, nursing other ill people, and other).

\section{Statistical analyses}

The KNHANES is a national cross-sectional survey that uses a complex sampling design. To appropriately represent the Korean population, the data were analyzed using the complex sample design while considering weight, cluster, and stratification (KCDC, 2013). The collected data were analyzed through SPSS 18.0 software. The characteristics of the subjects were analyzed using complex sample frequency analysis and descriptive statistics. The differences in the characteristics of the participants according to their employment status were analyzed through $\chi^{2}$ tests and simple linear regression. To verify the factors that affected employment situation, a complex sample logistic regression analysis was conducted. In the first step, a univariate logistic regression analysis was performed to identify the variables that could significantly affect employment situation. These variables were entered into a multivariable logistic regression analysis after adjusting for other factors. Two-tailed p-values less than .05 were considered statistically significant.

\section{Results}

\section{General characteristics}

The general characteristics of participants are shown in Table 1. Of the participants $62.1 \%$ was female. For the age groups, participants in their 20/30s, 40/50s and $60 \mathrm{~s}$ and above accounted for $8.0 \%, 44.4 \%$, and $47.6 \%$ of the sample, respectively. In addition, $78.2 \%$ of the participants were married and living with their spouses, and $77.9 \%$ of the participants were living in cities. As for income level,
Table 1. General Characteristics and Cancer-Related Factors of Cancer Survivors $(n=1,060)$

\begin{tabular}{|c|c|c|}
\hline \multirow[t]{2}{*}{ Characteristic /Categories } & \multicolumn{2}{|c|}{ Total $(\mathrm{n}=1,060,100 \%)$} \\
\hline & $\mathrm{N}$ & $\%$ \\
\hline \multicolumn{3}{|l|}{ General characteristics } \\
\hline \multicolumn{3}{|l|}{ Gender } \\
\hline Male & 390 & 37.9 \\
\hline Female & 670 & 62.1 \\
\hline \multicolumn{3}{|l|}{ Age (years) } \\
\hline $19-39$ & 58 & 8 \\
\hline $40-59$ & 383 & 44.4 \\
\hline$\geq 60$ & 619 & 47.6 \\
\hline \multicolumn{3}{|l|}{ Marital status } \\
\hline Married & 839 & 78.2 \\
\hline Single/divorced/separated/widowed & 221 & 21.8 \\
\hline \multicolumn{3}{|l|}{ Place of residence } \\
\hline Urban & 813 & 77.9 \\
\hline Rural & 247 & 22.1 \\
\hline \multicolumn{3}{|l|}{ Income } \\
\hline 1st quartile & 304 & 26.4 \\
\hline 2nd quartile & 272 & 26.3 \\
\hline 3rd quartile & 241 & 23.3 \\
\hline 4th quartile & 243 & 24 \\
\hline \multicolumn{3}{|l|}{ Education level } \\
\hline$\leq$ Middle school & 579 & 51.5 \\
\hline$\geq$ High school & 481 & 48.5 \\
\hline \multicolumn{3}{|l|}{ Cancer-related factors } \\
\hline \multicolumn{3}{|l|}{ Type of cancer } \\
\hline Stomach & 199 & 17.8 \\
\hline Liver & 30 & 3.2 \\
\hline Colon & 118 & 11.1 \\
\hline Lung & 32 & 2.2 \\
\hline Breast & 140 & 12.7 \\
\hline Cervix & 123 & 11.6 \\
\hline Thyroid & 175 & 17.9 \\
\hline Other & 243 & 23.5 \\
\hline \multicolumn{3}{|l|}{ Time since diagnosis (years) } \\
\hline$<5$ & 453 & 44.9 \\
\hline $9-10$ & 283 & 25.9 \\
\hline$\geq 10$ & 324 & 29.2 \\
\hline \multicolumn{3}{|l|}{ Full recovery } \\
\hline Yes & 578 & 54.1 \\
\hline No & 482 & 45.9 \\
\hline \multicolumn{3}{|l|}{ Ongoing treatment } \\
\hline Yes & 379 & 36.7 \\
\hline No & 681 & 63.3 \\
\hline \multicolumn{3}{|l|}{ Perceived health } \\
\hline Good & 206 & 18.5 \\
\hline Moderate & 471 & 45.7 \\
\hline Poor & 383 & 35.8 \\
\hline \multicolumn{3}{|l|}{ Activity limitation } \\
\hline Yes & 211 & 19.1 \\
\hline No & 849 & 80.9 \\
\hline
\end{tabular}

Asian Pacific Journal of Cancer Prevention, Vol 20 
Table 2. Employment Situation of Cancer Survivors $(n=1,060)$

\begin{tabular}{|c|c|c|c|c|}
\hline Employment Status & Characteristic & Categories & $\mathrm{N}$ & $\%$ \\
\hline \multirow[t]{13}{*}{ Employment $(\mathrm{n}=410,42.0 \%)$} & \multirow[t]{3}{*}{ Occupation classification $^{\text {a }}$ ) } & Administration/manager & 114 & 29.8 \\
\hline & & Service/sales & 82 & 22.4 \\
\hline & & Labor & 214 & 47.7 \\
\hline & \multirow[t]{3}{*}{ Status of workers ${ }^{a}$ ) } & Wage/salary worker & 203 & 52.9 \\
\hline & & Self-employed/employer & 156 & 34.9 \\
\hline & & Unpaid family worker & 51 & 12.2 \\
\hline & \multirow[t]{2}{*}{ Employment type of wage/salary workers ${ }^{b}$ ) } & Regular & 132 & 63.8 \\
\hline & & Non-regular & 71 & 36.2 \\
\hline & \multirow[t]{2}{*}{ Type of contract of wage/salary workers ${ }^{b}$ ) } & Full-time & 154 & 77.4 \\
\hline & & Part-time & 49 & 22.6 \\
\hline & \multirow[t]{3}{*}{ Average working hours per week ${ }^{a}$ ) } & $<40$ & 188 & 45 \\
\hline & & $40-51$ & 130 & 31.4 \\
\hline & & $\geq 52$ & 92 & 23.5 \\
\hline \multirow[t]{7}{*}{ Unemployment $(\mathrm{n}=650,58.0 \%)$} & \multirow[t]{7}{*}{ Reasons $^{c}$ ) } & Health-related reasons & 339 & 56 \\
\hline & & Lack of necessity & 145 & 19.9 \\
\hline & & Child care, nursing & 50 & 8.2 \\
\hline & & Retirement & 51 & 6.2 \\
\hline & & Between jobs & 44 & 6.3 \\
\hline & & Student or trainee & 4 & 1.3 \\
\hline & & Other & 17 & 2.1 \\
\hline
\end{tabular}

a), Employed cancer survivors $(\mathrm{n}=410)$; b), Wage/salary workers among the employed $(\mathrm{n}=203)$; $\mathrm{c}$ ), Cancer survivors without a job ( $\mathrm{n}=650)$.

the first quantile, which was the lowest, accounted for $26.4 \%$. Of all participants $51.5 \%$ had attained a middle school or lower level of education.

\section{Cancer-related factors}

Cancer survivors with thyroid cancer comprised $17.9 \%$, stomach cancer $17.8 \%$, and breast cancer $12.7 \%$ of the participants. Additionally, $44.9 \%$ of the participants had been diagnosed within the past five years and 29.2\% more than a decade ago, $45.9 \%$ of the participants were not fully cured of the disease and still had cancer, and $36.7 \%$ of the participants were still receiving cancer treatment. For perceived health, $45.7 \%$ of the participants described their health as moderate, $35.8 \%$ of the participants as poor, and $18.5 \%$ of the participants as good; and $19.1 \%$ of the s participants said that they had limitations in their daily life and social activities (Table 1).

\section{Employment situation of the cancer survivors}

Table 2 shows the employment status of the cancer survivors, with $42 \%(n=410)$ being employed and $58.0 \%$ $(\mathrm{n}=650)$ being unemployed. Of the employed subjects, $29.8 \%$ worked in administration/office jobs, $22.4 \%$ in services/sales, and $47.7 \%$ of the subjects in labor. As for worker status, $52.9 \%$ of the participants were wage/salary workers, $34.9 \%$ of the participants were self-employed or employers, and $12.2 \%$ of the participants were unpaid family workers. Of the wage/salary workers, $63.8 \%$ were regular employees, $77.4 \%$ worked full-time, and $23.5 \%$ of the employed participants worked more than 52 hours per week.

The reasons unemployed cancer survivors were not able to participate in economic activities were, in most cases, due to health conditions, which accounted for $56.0 \%$ of the participants, while $19.9 \%$ did not perceive a necessity to work.

Factors associated the employment situation of the cancer survivors

The univariate logistic analysis showed that several factors were associated with cancer survivors' employment status, including male gender $(\mathrm{OR}=2.11,95 \% \mathrm{CI}$ $1.56-2.87)$, younger age $(\mathrm{OR}=3.13,95 \%$ CI $1.65-5.94)$, living with a spouse $(\mathrm{OR}=2.13,95 \%$ CI 1.42-3.18), higher income level (OR=4.01, 95\% CI 2.68-6.00), educational level of middle school or under $(\mathrm{OR}=0.68$, 95\% CI 0.51-0.90), breast (OR=0.54, 95\% CI 0.31-0.96) and cervix $(\mathrm{OR}=0.43,95 \% \mathrm{CI} 0.24-0.77)$ cancer site, having good perceived health $(\mathrm{OR}=2.59,95 \%$ CI 1.69 $3.98)$, and not having activity limitation $(\mathrm{OR}=3.46,95 \%$ CI 2.21-5.42).

After adjusting for significant variables from the univariate analysis and performing a multivariate logistic regression analysis, the factors that increased the employment of cancer survivors included male gender $(\mathrm{aOR}=2.68,95 \% \mathrm{CI} 1.77-4.05)$, younger age $(\mathrm{aOR}=4.16$, 95\% CI 2.15-8.05), higher income level $(\mathrm{aOR}=2.59,95 \%$ CI1.57-4.28), educational level of middle school or under $(\mathrm{aOR}=1.70,95 \% \mathrm{CI} 1.17-2.46)$, and not having activity limitation $(\mathrm{aOR}=2.50,95 \%$ CI 1.49-4.18) (Table 3).

\section{Discussion}

The findings of this study were intended to be used 
DOI: 10.31557/APJCP.2019.20.1.33

Employment Situation among Cancer Survivors

Table 3. Characteristics of Cancer Survivors According to Employment Situation $(n=1,060)$

\begin{tabular}{|c|c|c|c|c|c|c|c|}
\hline \multirow[t]{2}{*}{ Characteristic } & \multirow[t]{2}{*}{ Categories } & \multicolumn{3}{|c|}{ Univariate } & \multicolumn{3}{|c|}{ Multivariate } \\
\hline & & OR & $95 \% \mathrm{CI}$ & $\mathrm{p}$ value & OR & $95 \% \mathrm{CI}$ & $\mathrm{p}$ value \\
\hline \multicolumn{8}{|l|}{ General characteristics } \\
\hline \multirow[t]{2}{*}{ Gender } & Male & 2.11 & $1.56-2.87$ & $<.001$ & 2.68 & $1.77-4.05$ & $<.001$ \\
\hline & Female & 1 & & & 1 & & \\
\hline \multirow[t]{3}{*}{ Age (years) } & $19-39$ & 3.13 & $1.65-5.94$ & $<.001$ & 4.16 & $2.15-8.05$ & $<.001$ \\
\hline & $40-59$ & 2.67 & $1.98-3.61$ & $<.001$ & 3.11 & $2.12-4.58$ & $<.001$ \\
\hline & $\geq 60$ & 1 & & & 1 & & \\
\hline \multirow[t]{2}{*}{ Marital status } & Married & 2.13 & $1.42-3.18$ & $<.001$ & 1.26 & $0.81-1.97$ & 0.304 \\
\hline & Single/divorced/separated/widowed & 1 & & & 1 & & \\
\hline \multirow[t]{2}{*}{ Region } & Urban & 0.75 & $0.53-1.04$ & 0.088 & & & \\
\hline & Rural & 1 & & & & & \\
\hline \multirow[t]{4}{*}{ Income } & 1st quartile & 1 & & & 1 & & \\
\hline & 2nd quartile & 2.74 & $1.79-4.19$ & $<.001$ & 2.23 & $1.38-3.61$ & 0.001 \\
\hline & 3rd quartile & 3.08 & $2.05-4.62$ & $<.001$ & 1.92 & $1.19-3.09$ & 0.007 \\
\hline & 4th quartile & 4.01 & $2.68-6.00$ & $<.001$ & 2.59 & $1.57-4.28$ & $<.001$ \\
\hline \multirow[t]{2}{*}{ Education level } & $\leq$ Middle school & 0.68 & $0.51-0.90$ & 0.007 & 1.7 & $1.17-2.46$ & 0.005 \\
\hline & $\geq$ High school & 1 & & & 1 & & \\
\hline \multicolumn{8}{|l|}{ Cancer-related factors } \\
\hline \multirow[t]{8}{*}{ Cancer Site } & Stomach & 0.93 & $0.56-1.52$ & 0.766 & & & \\
\hline & Liver & 0.9 & $0.36-2.24$ & 0.815 & & & \\
\hline & Colorectal & 0.82 & $0.46-1.45$ & 0.49 & & & \\
\hline & Lung & 0.98 & $0.39-2.49$ & 0.965 & & & \\
\hline & Breast & 0.54 & $0.31-0.96$ & 0.035 & 0.89 & $0.48-1.64$ & 0.711 \\
\hline & Cervix & 0.43 & $0.24-0.77$ & 0.005 & 0.84 & $0.45-1.59$ & 0.596 \\
\hline & Other cancers & 0.69 & $0.42-1.14$ & 0.145 & & & \\
\hline & Thyroid & 1 & & & 1 & & \\
\hline Time & $<5$ & 0.84 & $0.60-1.20$ & 0.338 & & & \\
\hline \multirow[t]{2}{*}{ since diagnosis (years) } & $9-10$ & 1.09 & $0.73-1.63$ & 0.669 & & & \\
\hline & $\geq 10$ & 1 & & & & & \\
\hline \multirow[t]{2}{*}{ Full recovery } & Yes & 1.24 & $0.91-1.68$ & 0.17 & & & \\
\hline & No & 1 & & & & & \\
\hline \multirow[t]{2}{*}{ Ongoing treatment } & Yes & 1.07 & $0.78-1.46$ & 0.695 & & & \\
\hline & No & 1 & & & & & \\
\hline \multirow[t]{3}{*}{ Perceived health } & Good & 2.59 & $1.69-3.98$ & $<.001$ & 1.47 & $0.92-2.34$ & 0.711 \\
\hline & Moderate & 1.84 & $1.30-2.61$ & 0.001 & 1.19 & $0.80-1.76$ & 0.596 \\
\hline & Poor & 1 & & & & & \\
\hline \multirow[t]{2}{*}{ Activity limitation } & Yes & 1 & & & 1 & & \\
\hline & No & 3.46 & $2.21-5.42$ & $<.001$ & 2.5 & $1.49-4.18$ & 0.001 \\
\hline
\end{tabular}

as baseline data for factors associated with employment status of cancer survivors. In our study, $42.0 \%$ of cancer survivors were employed, and the unemployment rate (unemployed persons/cancer survivors 19 years and older x100) was $58.0 \%$. A cohort study conducted by Taskila and Lindbohm (2007) found that the employment rate among cancer patients, was $78 \%$ and did not greatly differ from that of the normal population before the diagnosis, but was reduced to $64 \%$ in the 2.5 years after the diagnosis. In addition, it was significantly lower than the $73 \%$ employment rate of the normal population. Likewise, a study conducted by Maunsell et al., (2004) in breast cancer survivors showed that survivors had a 1.29-fold chance of losing their job within the three years after the diagnosis compared to the normal population. Furthermore, Ahn et al., (2009) reported in a study on breast cancer survivors that although the employment rate of the female population was $52.1 \%$, the employment rate among breast cancer survivors after completing treatment was significantly lower, i.e., only $33.2 \%$. Also, a review of the related studies indicated that while it was difficult to provide a direct figure, cancer survivors compared to the general population, showed a lower employment rate and a higher unemployment rate. 
As for the employment situation, in $42 \%$ of the cancer survivors that were actually working, 52.9\% were wage/salary workers, $63.8 \%$ of whom were regular workers and $36.2 \%$ non-regular. These results are similar to the figures in the March 2016 Economically Active Population Survey, in which $68.0 \%$ of the subjects were working as regulars and $32.0 \%$ as non-regulars. Moreover, $23.5 \%$ of the employed persons were working more than 52 hours a week, which was 12 hours longer than the legal working limit of 40 hours a week. According to the 2014 OECD statistics, the average working hours of employed persons in South Korea was the third longest of all OECD member states and 1.6 times more than that of Germany (OECD, 2014). It is common for many cancer survivors and ordinary workers to be non-regulars or to work longer than the legal working hours. This is an issue that the government should address through policies to ensure that all workers, irrespective of health status, can work appropriate hours.

Based on the multivariate logistic regression analysis conducted to identify the factors affecting the employment situation of cancer survivors, certain characteristics, such as male gender, younger age, higher income level, middle school or lower level of education, and lack of activity limitation, were found to be statistically significant factors.

Male cancer survivors had a higher likelihood of being employed than female survivors. However, other studies on the influence of gender on employment status show conflicting results. That is, studies conducted by Choi et al., (2007) who used Korean National Health Insurance data, and Lee et al., (2008) who studied stomach cancer survivors, show findings that are in line with our study. However, Kim et al., (2014) reported that the difference due to gender and employment status were not significantly associated. Furthermore, many studies conducted in Western countries report that gender does not affect their employment situation (Spelten et al., 2002; Sesto et al., 2013; Tevaarwerk et al., 2016). In our study, participants in $20 / 30$ s and $40 / 50$ s, who represent the relatively younger groups, had increased odds of being employed compared to the older group of those 60 years old and above. This finding is in line with the results of previous studies (Schultz et al., 2002; Sesto et al., 2013; Yoo et al., 2013; Kim et al., 2014). For the older age group it is more likely for the diagnosis of cancer to occur at the same time as their retirement or at a time at which they are trying to reduce the intensity of their work. In addition, older individuals are more likely to stop working due to the physical limitations caused by cancer treatment (Kim et al., 2014).

In our study, as income level increases, the odds ratio of being employed also increases. This result is in line with the findings of previous studies (Choi et al., 2007; Ahn et al., 2009; Park et al., 2009) who all reported that a high income level was associated with a higher chance of employment. However, the results regarding educational level differed, as the lower educational level group was more likely to be employed than those with a higher educational level of high school or beyond. This relationship between educational level and employment situation conflicts with results of previous study. That is, in a study on breast cancer survivors in South Korea, lower educational level was associated with a significant increase in the odds of unemployment (Ahn et al., 2009). Among stomach cancer survivors, the employment ratio was higher in those who were high school graduates or beyond, at $63.0 \%$, compared to the $40.0 \%$ of the lower education group (Lee et al., 2008). This proportion is equal to that found in studies targeting the general population. According to Clarke et al., (2015) compared to persons with a level of education lower than high school, the chance of employment was two times higher for people who had a high school level of education or beyond and 2.6 times higher for college graduates, meaning that the higher the educational level of the participants was, the more likely it was for the participants to be employed. For cancer survivors with a higher education and income level, it is more likely that they are working in a white-collar job, which is associated with a higher social situation that makes it easier for these individuals to return to their original jobs. In addition, they may be able to take medical leave, thereby avoiding the possibility of unemployment (Park et al., 2009). However, in this study, most of the participants in the employment group $(47.7 \%)$ had manual labor jobs. Therefore, we think that educational level did not have a large effect on the employment status of participants. Furthermore, while cancer survivors in other countries are highly motivated to work in order to maintain their health coverage, it is believed that this factor is not significant in settings with a national health insurance system, medical aid program, and employment insurance such as the setting found in South Korea (Choi et al., 2007; Park et al., 2009). All employed and self-employed individuals and their dependents can receive health care benefits (National Health Insurance Service, 2010). The findings in this paper imply that future researchers should consider not only the general and cancer-related characteristics of participants but also the relevant health insurance system in order to understand employment in cancer survivors. We have shown that the national health insurance service in South Korea, which covers all Korean citizens, reduces the burden of health care cost among cancer survivors.

In this study, cancer-related factors, such as the type of cancer, complete recovery and treatment, and the time elapsed since the diagnosis, were not associated to the participants' employment situation. Previous studies, in which the relationship between employment status and type of cancer were addressed, show different results. That is, cancers of the liver (Choi et al., 2007), breast (Sesto et al., 2013), prostate (Sesto et al., 2013), and colon (Taskila and Lindbohm, 2007; Sesto et al., 2013) were not significantly associated with employment, whereas liver (Park et al., 2009), pancreas (Park et al., 2009), lung (Schultz et al., 2002; Taskila and Lindbohm, 2007; Park et al., 2009), blood and lymph (Taskila and Lindbohm, 2007; Park et al., 2009), head and neck (Schultz et al., 2002), and central nervous system cancers (Taskila and Lindbohm, 2007; Park et al., 2009) were related to a lower chance of employment. The types of cancer that negatively affected chances of employment were associated with lower chances of survival, were more 
focalized and had a higher chance of requiring systemic treatments. In particular, cancers of the central nervous system are more likely to cause problems with subjects' activities or cognitive abilities (Spelten et al., 2002). In contrast, Park et al., (2009) proved that all cancers, except thyroid cancer, were related to prolonged unemployment. This result is consistent with the results of the univariate logistic regression in our study, in which individuals with breast or cervical cancer were significantly more likely to be unemployed compared to those with thyroid cancer. In our study, the types of cancer were classified into stomach, colon, liver, lung, breast, uterus, thyroid, and other cancers. It is likely that the various types of cancer included in the 'other cancers' category could be composed of cancers with different severity levels. Future studies should divide cancer types in a more detailed manner to ensure that the relationship between the type of cancer and the employment status of the subjects can be identified. In addition, with regard to the current treatment status of our participants, in previous studies the chances of unemployment were reported as higher with systemic treatment compared to local treatment, such as chemical, radiation, and marrow transplant (Ahn et al., 2009; Short et al., 2005). It is necessary to consider what type of treatment is being treated, rather than simply asking whether the patient is being treated.

In our study, time elapsed since the diagnosis did not affect the employment situation. This finding is in line with previous studies (Ahn et al., 2009; Clarke et al., 2015). In earlier studies, the disease phase of the cancer (Choi et al., 2007), rather than the elapsed time, had been found to be negatively associated with the employment situation. This may be because the cancer survivors' condition is compromised and the life expectancy likely to be more limited with advanced stages (Choi et al., 2007). If the cancer survivors experience activity limitations, their chance of becoming employed is significantly lower. This result is in line with those of previous studies (Feuerstein, 2005; Lee et al., 2008; Short et al., 2008; Clarke et al., 2015). This notion is supported by the findings of this study, in which health issues accounted for $53.6 \%$ of the reasons for unemployment, and is in line with previous studies (Maunsell et al., 2004). Therefore, support programs for return to work such as a tailored multidisciplinary intervention (van Egmond et al., 2015) for cancer survivors needs to be developed.

As for the limitations of this study, as the participants only completed the survey once, it was not possible to identify the chronological order between employment situation and other factors, and it was not possible to determine causal relationships. As the researchers used secondary data, the operational definitions of the variables included in this study differed from those used in previous studies, thereby making further comparisons difficult.

\section{Statement conflict of Interest}

The authors declared no potential conflicts of interest with respect to the research, authorship, and publication of this article.

\section{References}

Ahn E, Cho J, Shin DW, et al (2009). Impact of breast cancer diagnosis and treatment on work-related life and factors affecting them. Breast Cancer Res Treat, 116, 609-16.

American Cancer Society (2016). Cancer Treatment and Survivorships Fact and Figures 2014-1015. Available at: http://www.cancer.org/acs/groups/content/@research/ documents/document/acspc-042801.pdf (accessed 27 August 2016).

Amir Z, Brocky J (2009). Cancer survivorship and employment: epidemiology. Occup Med (Lond), 59, 373-7.

Amir Z, Neary D, Luker K (2008). Cancer survivors' views of work 3 years post diagnosis: a UK perspective. Eur J Oncol Nurs, 12, 190-7.

Choi KS, Kim EJ, Lim JH, et al (2007). Job loss and reemployment after a cancer diagnosis in Koreans - a prospective cohort study. Psychooncology, 16, 205-13.

Clarke TC, Christ SL, Soler-Vila H, et al (2015). Working with cancer: health and employment among cancer survivors. Ann Epidemiol, 25, 832-8.

Cooper AF, Hankins M, Rixon L, Eaton E, Grunfeld EA (2013). Distinct work-related, clinical and psychological factors predict return to work following treatment in four different cancer types. Psychooncology, 22, 659-67.

Feuerstein M (2005). Cancer survivorship and work. J Occup Rehabil, 15, 1-2.

Gibson SM (1998). The Americans with disabilities act protects individuals with a history of cancer from employment discrimination: Myth or Reality. Hofstra Lab Emp, 16, 167-200.

Grunfeld EA, Low E, Cooper AF (2010). Cancer survivors' and employers' perceptions of working following cancer treatment. Occup Med (Lond), 60, 611-7.

Kim YA, Yun YH, Chang YJ, et al (2014). Employment status and work-related difficulties in lung cancer survivors compared with the general population. Ann Surg, 259, 569-75.

Korea Centers for Disease Control and Prevention (2013). The Fifth (2010-2012) Korea National Health and Nutrition Examination Survey. Guidebook for database. Ministry of Health and Welfare, Sejong-shi.

Lee MK, Lee KM, Bae JM, et al (2008). Employment status and work-related difficulties in stomach cancer survivors compared with the general population. Br J Cancer, 98, 708-15.

Lee SJ, Koo DW, Oh YS (2010). Eco-social development: an empirical and theoretical research. Arche, Seoul.

Lindbohm ML, Kuosma E, Taskila T, et al (2014). Early retirement and non-employment after breast cancer. Psychooncology, 23, 634-41.

Maunsell E, Drolet M, Brisson J, et al (2004). Work situation after breast cancer: results from a population-based study. J Natl Cancer Inst, 96, 1813-22.

Mehnert A (2011). Employment and work-related issues in cancer survivors. Crit Rev Oncol Hematol, 77, 109-30.

National Cancer Information Center (2016). Available at: https:// www.cancer.go.kr/lay1/S1T648C651/contents.do (accessed 19 August 2016).

National Health Insurance Service (2010). Insurance benefits: web site. Available at: http://www.nhis.or.kr/static/html/ wbd/g/a/wbdga0405.html (accessed 30 May 2017).

Nekhlyudov L, Walker R, Ziebell R, et al (2016). Cancer survivors' experiences with insurance, finances, and employment: results from a multisite study. J Cancer Surviv, 10, 1104-11.

OECD (2014). Available at: https://data.oecd.org/emp/hoursworked.htm (accessed 27 August 2016). 
OECD (2017). Employment rate (indicator): web site. Available at: https://data.oecd.org/emp/employment-rate. htm (accessed 30 May 2017).

Park JH, Park JH, Kim SG (2009). Effect of cancer diagnosis on patient employment status: a nationwide longitudinal study in Korea. Psychooncology, 18, 691-9.

Schultz PN, Beck ML, Stava C, Sellin RV (2002). Cancer survivors. Work related issues. AAOHN, 50, 220-6.

Sesto ME, Faatin M, Wang S, Tevaarwerk AJ, Wiegmann DA (2013). Employment and retirement status of older cancer survivors compared to non-cancer siblings. Work, 46, 445-53.

Short PF, Vasey JJ, Belue R (2008). Work disability associated with cancer survivorship and other chronic conditions. Psychooncology, 17, 91-7.

Short PF, Vasey JJ, Tunceli K (2005). Employment pathways in a large cohort of adult cancer survivors. Cancer, 103, 1292-301.

Spelten ER, Sprangers MA, Verbeek JH (2002). Factors reported to influence the return to work of cancer survivors: a literature review. Psychooncology, 11, 124-31.

Statistics Korea (2016a). Cancer survivial rate: web site. Available at: http://www.index.go.kr/potal/main/EachDtlPageDetail. do?idx_cd=2935 (accessed 19 August 2016).

Statistics Korea (2016b). Local Area Labour Force Survey: web site. Available at: http://meta.narastat.kr/metasvc/index. do?iemInputNo=0000123765834 (accessed 30 May 2017).

Stewart B, Wild CP (2014). World Cancer Report. World Health Organization.

Taskila T, Lindbohm ML (2007). Factors affecting cancer survivors' employment and work ability. Acta Oncol, 46, 446-51.

Teo I, Reece GP, Christie IC, et al (2016). Body image and quality of life of breast cancer patients: influence of timing and stage of breast reconstruction. Psychooncology, 25, 1106-12.

Tevaarwerk AJ, Lee JW, Terhaar A, et al (2016). Working after a metastatic cancer diagnosis: Factors affecting employment in the metastatic setting from ECOG-ACRIN's Symptom Outcomes and Practice Patterns study. Cancer, 122, 438-46.

van Egmond MP, Duijts SF, Vermeulen SJ, van der Beek AJ, Anema JR (2015). Return to work in sick-listed cancer survivors with job loss: design of a randomised controlled trial. BMC Cancer, 15, 63-73.

van Muijen P, Weevers NL, Snels IA, et al (2013). Predictors of return to work and employment in cancer survivors: a systematic review. Eur J Cancer Care, 22, 144-60.

Yoo SH, Yun YH, Park S, et al (2013). The correlates of unemployment and its association with quality of life in cervical cancer survivors. J Gynecol Oncol, 24, 367-75.

This work is licensed under a Creative Commons AttributionNon Commercial 4.0 International License. 